NASA/TM-2010-216252

\title{
Orion Active Thermal Control System Dynamic Modeling Using Simulink/MATLAB
}

Xiao-Yen J. Wang and James Yuko

Glenn Research Center, Cleveland, Ohio 


\section{NASA STI Program . . . in Profile}

Since its founding, NASA has been dedicated to the advancement of aeronautics and space science. The NASA Scientific and Technical Information (STI) program plays a key part in helping NASA maintain this important role.

The NASA STI Program operates under the auspices of the Agency Chief Information Officer. It collects, organizes, provides for archiving, and disseminates NASA's STI. The NASA STI program provides access to the NASA Aeronautics and Space Database and its public interface, the NASA Technical Reports Server, thus providing one of the largest collections of aeronautical and space science STI in the world. Results are published in both non-NASA channels and by NASA in the NASA STI Report Series, which includes the following report types:

- TECHNICAL PUBLICATION. Reports of completed research or a major significant phase of research that present the results of NASA programs and include extensive data or theoretical analysis. Includes compilations of significant scientific and technical data and information deemed to be of continuing reference value. NASA counterpart of peer-reviewed formal professional papers but has less stringent limitations on manuscript length and extent of graphic presentations.

- TECHNICAL MEMORANDUM. Scientific and technical findings that are preliminary or of specialized interest, e.g., quick release reports, working papers, and bibliographies that contain minimal annotation. Does not contain extensive analysis.

- CONTRACTOR REPORT. Scientific and technical findings by NASA-sponsored contractors and grantees.
- CONFERENCE PUBLICATION. Collected papers from scientific and technical conferences, symposia, seminars, or other meetings sponsored or cosponsored by NASA.

- SPECIAL PUBLICATION. Scientific, technical, or historical information from NASA programs, projects, and missions, often concerned with subjects having substantial public interest.

- TECHNICAL TRANSLATION. Englishlanguage translations of foreign scientific and technical material pertinent to NASA's mission.

Specialized services also include creating custom thesauri, building customized databases, organizing and publishing research results.

For more information about the NASA STI program, see the following:

- Access the NASA STI program home page at http://www.sti.nasa.gov

- E-mail your question via the Internet to help@ sti.nasa.gov

- Fax your question to the NASA STI Help Desk at 443-757-5803

- Telephone the NASA STI Help Desk at 443-757-5802

- Write to: NASA Center for AeroSpace Information (CASI) 7115 Standard Drive Hanover, MD 21076-1320 
NASA/TM-2010-216252

\section{Orion Active Thermal Control System Dynamic Modeling Using Simulink/MATLAB}

Xiao-Yen J. Wang and James Yuko

Glenn Research Center, Cleveland, Ohio

Prepared for the

48th Aerospace Sciences Meeting

sponsored by the American Institute of Aeronautics and Astronautics

Orlando, Florida, January 4-7, 2010

National Aeronautics and

Space Administration

Glenn Research Center

Cleveland, Ohio 44135 


\section{Acknowledgments}

The authors thank Thomas Haregot at Lockheed Martin for providing critical data for the modeling effort and Stephen Miller at the NASA Johnson Space Center for providing the attitude definition for the 45-hr nominal mission timeline.

This report contains preliminary findings, subject to revision as analysis proceeds.

Trade names and trademarks are used in this report for identification only. Their usage does not constitute an official endorsement, either expressed or implied, by the National Aeronautics and Space Administration.

Level of Review: This material has been technically reviewed by technical management.

Available from

NASA Center for Aerospace Information 7115 Standard Drive

Hanover, MD 21076-1320
National Technical Information Service 5301 Shawnee Road Alexandria, VA 22312

Available electronically at http://gltrs.grc.nasa.gov 


\title{
Orion Active Thermal Control System Dynamic Modeling Using Simulink/MATLAB
}

\author{
Xiao-Yen J. Wang and James Yuko \\ National Aeronautics and Space Administration \\ Glenn Research Center \\ Cleveland, Ohio 44135
}

\begin{abstract}
This paper presents dynamic modeling of the crew exploration vehicle (Orion) active thermal control system (ATCS) using Simulink (Ref. 1). The model includes major components in ATCS, such as heat exchangers and radiator panels. The mathematical models of the heat exchanger and radiator are described first. Four different orbits were used to validate the radiator model. The current model results were compared with an independent Thermal Desktop (Ref. 2) (TD) model results and showed good agreement for all orbits. In addition, the Orion ATCS performance was presented for three orbits and the current model results were compared with three sets of solutions-FloCAD (Ref. 3) model results, SINDA/FLUINT (Ref. 4) model results, and independent Simulink model results. For each case, the fluid temperatures at every component on both the crew module and service module sides were plotted and compared. The overall agreement is reasonable for all orbits, with similar behavior and trends for the system. Some discrepancies exist because the control algorithm might vary from model to model. Finally, the ATCS performance for a 45-hr nominal mission timeline was simulated to demonstrate the capability of the model. The results show that the ATCS performs as expected and approximately $2.3 \mathrm{lb}$ water was consumed in the sublimator within the $45 \mathrm{hr}$ timeline before Orion docked at the International Space Station.
\end{abstract}

\section{Introduction}

The Orion project is under the Constellation program for the space exploration vision initiated by President Bush in 2004. The Constellation program is responsible for providing the elements that will transport humans and cargo to both the International Space Station (ISS) and the Moon. These elements are the crew exploration vehicle (Orion), the crew launch vehicle (Ares I), the lunar surface access module (Altair), and the cargo launch vehicle (Ares V). Orion, with a crew of up to four astronauts, will launch on Ares I and then use its main engine to insert itself into a safe orbit to either dock with the ISS or with Altair. For ISS missions, Orion will be responsible for separation, entry, descent, and landing. For lunar missions, Orion also will have to maintain itself in low lunar orbit and perform a trans-Earth injection maneuver to return from the Moon. Orion consists of the launch abort system (LAS), crew module (CM), service module (SM), and spacecraft adapter (SA). The CM is a capsule design that provides the primary structure for crew support, incorporates the bulk of the avionics systems, and provides the capability for entry and parachute landing. The LAS will safely extract the CM from the launch configuration in the event of an early launch abort. The SM, the structure on which the CM rests, interfaces with Ares I. It will perform in-space flight propulsion operations and power generation and provide the heat rejection for the Orion active thermal control system.

This study focuses on Orion's ATCS. The purpose of the ATCS is to control the crew environment inside the CM, while maintaining the temperature of all avionics under their temperature limits. As shown in Figure 1, two CM fluid loops will pass through the CM, take heat generated inside the CM and from all electronics, then pass the heat to the SM fluid loops through two interface heat exchangers (IFHXs). The SM fluid loops will carry the heat to the radiator panels and radiate the heat to space. On the CM side, there will be a phase-change 


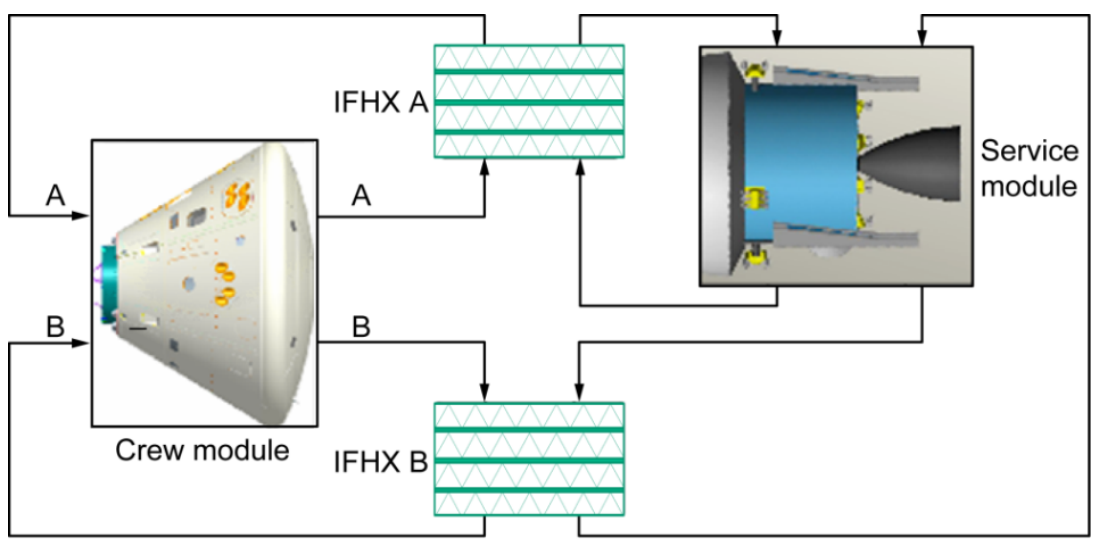

Figure 1.-Orion ATCS. IFHX, interface heat exchanger.

material (PCM) heat exchanger (HX) and a sublimator for the purpose of thermal topping. The control loop will have several set points, such as the fluid temperature entering the $\mathrm{CM}$ and the maximum temperature at the cold plates associated with the batteries on the SM. There will be a bypass flow path at the upstream of the IFHX on the CM side and a bypass flow path before the regenerative heat exchanger (Regen HX) on the SM side.

The current modeling effort is part of independent validation and verification (IV\&V) of the analysis results. Simulink and MATLAB are used to build a dynamic model independently to simulate the Orion ATCS. The model includes all major components in the ATCS, such as the cabin HX and cold plates on both CM and SM sides, IFHX, Regen HX, and the radiator with fluid loops on the SM side. The control system also is modeled to meet the thermal requirement for the ATCS. The user must define the initial conditions and provide the ambient radiation sink temperature for the radiator. This model focuses on the thermal performance of the ATCS. The hydraulic performance of the pump and the pressure drop at each component in the ATCS are not reported here.

In the following sections, the mathematical models of the HX and the radiator with the fluid loops are described first, followed by the validation of the ATCS radiator model using four different orbits. The numerical results are compared with the corresponding results from independent resources. The performance of the ATCS is presented for a 45-hr nominal mission timeline; then conclusions are drawn.

\section{Nomenclature}

$\begin{array}{ll}A & \text { heat transfer area } \\ A_{p} & \text { radiator panel area } \\ A_{p, i} & \text { area of the three sections on the panel (where } i=1,2,3 \text { ) } \\ C_{p, c} & \text { specific heat of cold fluid in heat exchanger } \\ C_{p, f} & \text { specific heat of fluid in heat exchanger } \\ C_{p, H X} & \text { specific heat of heat exchanger } \\ C_{p, h} & \text { specific heat of hot fluid in heat exchanger } \\ C_{p, r} & \text { specific heat of radiator panel } \\ D h & \text { hydraulic diameter of the fluid channel } \\ h A_{\text {cold }} & \text { heat transfer rate for cold fluid in heat exchanger } \\ h A_{\text {hot }} & \text { heat transfer rate for hot fluid in heat exchanger } \\ k & \text { thermal conductivity of the fluid }\end{array}$




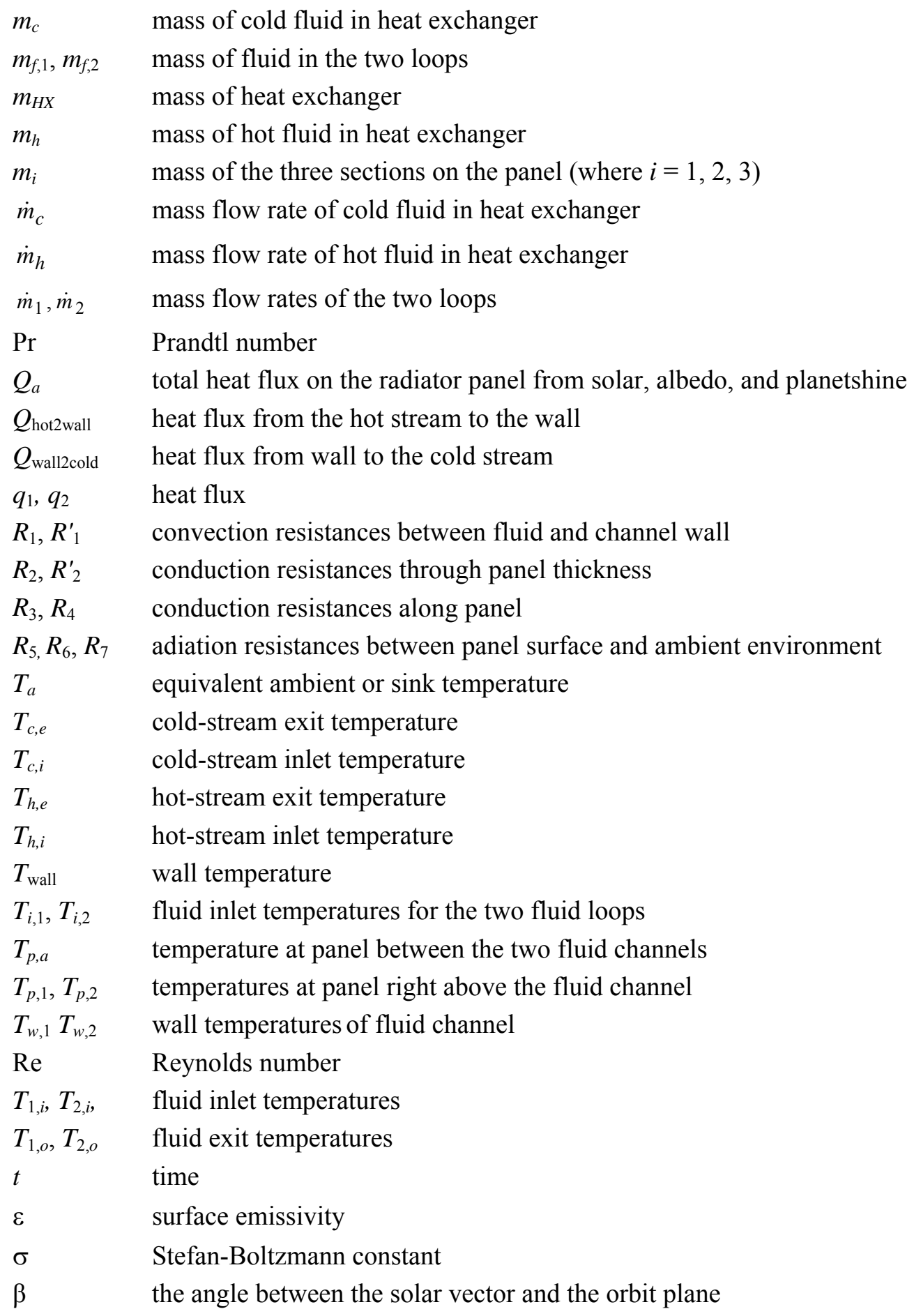

\section{Mathematical Models of the Heat Exchanger and Radiator}

One-Dimensional Transient Model for the Heat Exchanger

The heat exchanger considered here is a typical compact HX with plain-fin surfaces as shown in Figure 2. It is in a counter-flow arrangement. 
The inlet and exit temperatures are $T_{h, i}$ and $T_{h, e}$, respectively, for the hot-stream, $T_{c, i}$ and $T_{c, e .}$ for the cold-stream. Given the inlet temperature of both sides, $T_{h, e}, T_{c, e}$, and the wall temperature $T_{\text {wall }}$ can be solved through the following ordinary differential equations:

$$
\begin{aligned}
& \frac{d T_{h, e}}{d t}=\left(-Q_{\text {hot2wall }}+\dot{m}_{h} c_{p, h}\left(T_{h, i}-T_{h, e}\right)\right) /\left(m_{h} c_{p, h}\right) \\
& \frac{d T_{c, e}}{d t}=\left(Q_{\text {wall2cold }}+\dot{m}_{c} c_{p, c}\left(T_{c, i}-T_{c, e}\right)\right) /\left(m_{c} c_{p, c}\right) \\
& \frac{d T_{\text {wall }}}{d t}=\left(Q_{\text {hot2wall }}-Q_{\text {wall2cold }}\right) /\left(m_{H X} c_{p, H X}\right)
\end{aligned}
$$

where

$$
\begin{aligned}
& Q_{\text {hot } 2 \text { wall }}=h A_{\text {hot }}\left(\left(T_{h, i}+T_{h, e}\right) / 2-T_{\text {wall }}\right) \\
& Q_{\text {wall2cold }}=h A_{\text {cold }}\left(T_{\text {wall }}-\left(T_{c, i}+T_{c, e}\right) / 2\right)
\end{aligned}
$$

$t$ is time; $Q_{\text {hot2wall }}$ and $Q_{\text {wall2cold }}$ are the heat flux from the hot stream to the wall and from the wall to the cold stream; $h A_{\text {hot }}$ and $h A_{\text {cold }}$ are the heat transfer rates for the hot and cold fluids; $m_{h}, m_{c}$, and $m_{H X}$ are the masses of the hot fluid, cold fluid, and the heat exchanger itself; $c_{p, h}, c_{p, c}$, and $c_{p, H X}$ are the specific heats of the hot fluid, cold fluid, and heat exchanger; and $\dot{m}_{h}$ and $\dot{m}_{c}$ are the mass flow rates of the hot and cold fluids, respectively.

\section{One-Dimensional Transient Model of the Radiator Panel With Fluid Loops}

The radiator panel has a thin surface with fluid channels attached at its interior surface. The interior surface is covered by multilayer insulation (MLI) blankets. The exterior surface is coated with material that has high emissivity. The fluid loop will come into the header and split the flow through a number of channels along the panel. For the two-loop (A and B) flow configuration, the channel will flow alternately along fluid loops $\mathrm{A}$ and $\mathrm{B}$. The flow condition in the two loops can be different. A cross section of the radiator panel in the flow direction (sketched in Fig. 3) shows the two neighboring fluid channels denoted as loop A and loop B. On the exterior surface of the radiator panel, $T_{p, 1}$ and $T_{p, 2}$ are the temperatures at the panel right above the fluid channel, $T_{p, a}$ is the temperature at the panel between the two fluid channels, and $T_{w, 1}$ and $T_{w, 2}$ are the wall temperatures of the fluid channel.

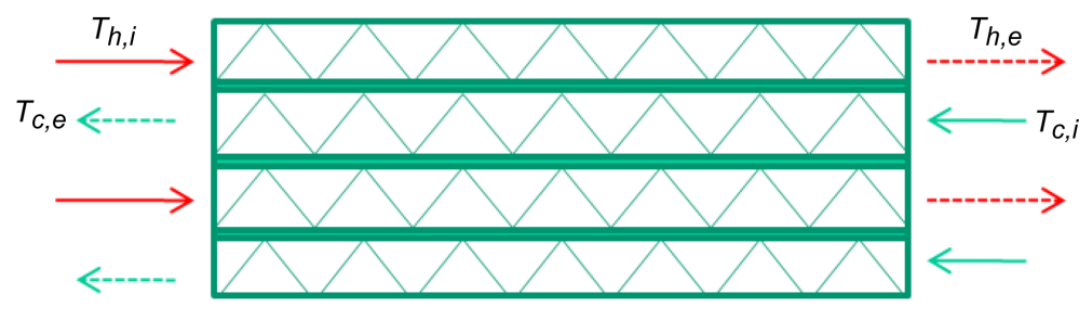

Figure 2.-Counter-flow heat exchanger (HX). 


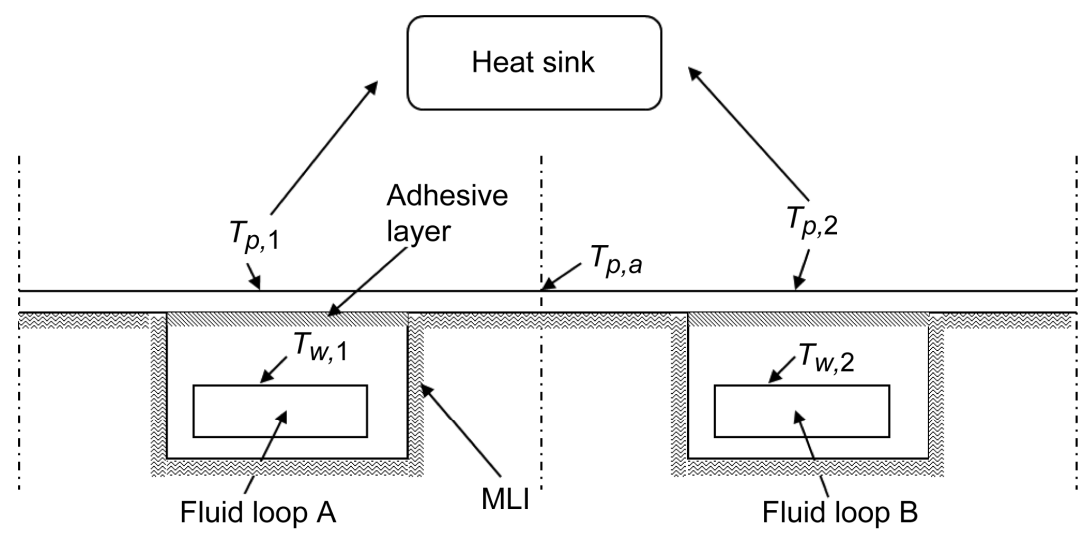

Figure 3.- Section of radiator panel showing the two fluid loops: A and B. MLI, multilayer insulation.

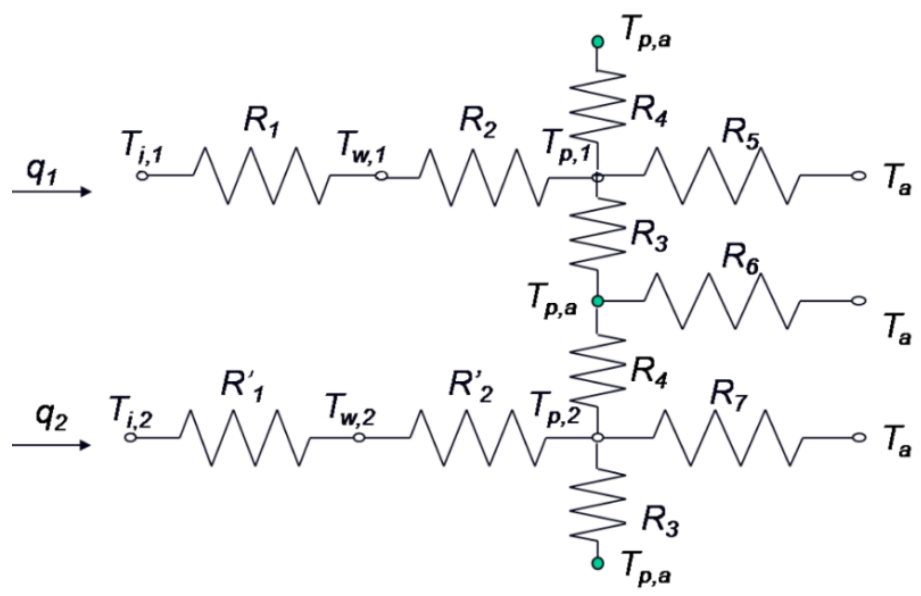

Figure 4.-Thermal circuit for radiator panel.

The corresponding thermal circuit is plotted in Figure 4. $R_{1}$ and $R_{1}^{\prime}$ are the convection resistances between the fluid and the channel wall; $R_{2}$ and $R_{2}^{\prime}$ are the conduction resistances through the panel and the adhesive layer thickness; $R_{3}$ and $R_{4}$ are the conduction resistances along the panel; $R_{5}, R_{6}$, and $R_{7}$ are the radiation resistances between the panel surface and the ambient environment; $T_{i, 1}$ and $T_{i, 2}$ are the fluid inlet temperatures for the two fluid loops (assumed to be given); and $T_{a}$ is the equivalent ambient or radiation sink temperature. In space, the radiator panel is exposed to the Sun, the planet, and deep space. For this model, $Q_{a}$ is the total heat flux from the Sun, albedo, and planetshine on the radiator panel. It is assumed that $Q_{a}=A_{p} \sigma \varepsilon T_{a}^{4}$, with $A_{p}$ being the radiator panel area, $\sigma$ the Stefan-Boltzmann Constant, and $\varepsilon$ the surface emissivity. Then the radiation sink temperature $T_{a}$ can be used to represent the ambient condition. For all cases, the sink temperatures were computed using a separate Thermal Desktop model and were used as input to the Simulink model. The Thermal Desktop model performed full threedimensional transient analysis for orbit heating on all the radiator panels and averaged the results over the entire panel to generate one sink temperature for each panel. Radiation between the large structures, such as solar arrays and radiator panels, is included in the model.

In the model, $m_{i}$ and $A_{p, i}$ (where $i=1,2,3$ ) denote the mass and the area of the three sections of the panel; $c_{p, r}$ and $c_{p, f}$ are the specific heats of the radiator panel and the fluid, $m_{f, 1}$ and $m_{f, 2}$ are the masses of the fluid in the two loops, and $\dot{m}_{1}$ and $\dot{m}_{2}$ are the mass flow rates of the two loops. The equations for 
solving the three panel wall temperatures, $T_{p, 1}, T_{p, 2}$, and $T_{p, a}$, and two fluid exit temperatures, $T_{1, o}$ and $T_{2, o}$, follow:

$$
\begin{aligned}
& m_{1} c_{p, r} \frac{\partial T_{p, 1}}{\partial t}=q_{1}-\frac{2\left(T_{p, 1}-T_{p, a}\right)}{R_{3}}-A_{p, 1} \sigma \varepsilon\left(T_{p, 1}^{4}-T_{a}^{4}\right) \\
& m_{2} c_{p, r} \frac{\partial T_{p, 2}}{\partial t}=q_{2}-\frac{2\left(T_{p, 2}-T_{p, a}\right)}{R_{4}}-A_{p, 2} \sigma \varepsilon\left(T_{p, 2}^{4}-T_{a}^{4}\right) \\
& m_{3} c_{p, r} \frac{\partial T_{p, a}}{\partial t}=\frac{2\left(T_{p, 1}-T_{p, a}\right)}{R_{3}}+\frac{2\left(T_{p, 2}-T_{p, a}\right)}{R_{4}}-A_{p, 3} \sigma \varepsilon\left(T_{p, a}^{4}-T_{a}^{4}\right) \\
& m_{f, 1} c_{p, f} \frac{\partial T_{1, o}}{\partial t}=-q_{1}+\dot{m}_{1} c_{p, f}\left(T_{1, i}-T_{1, o}\right) \\
& m_{f, 2} c_{p, f} \frac{\partial T_{2, o}}{\partial t}=-q_{2}+\dot{m}_{2} c_{p, f}\left(T_{2, i}-T_{2, o}\right)
\end{aligned}
$$

where

$$
\begin{aligned}
& q_{1}=h A\left(\left(T_{1, i}+T_{1, o}\right) / 2-T_{p, 1}\right) \\
& q_{2}=h A\left(\left(T_{2, i}+T_{2, o}\right) / 2-T_{p, 2}\right)
\end{aligned}
$$

with

$$
\begin{aligned}
& h A=7.54 k A / D h \quad \text { for } \operatorname{Re} \leq 2000 \\
& h A=0.023 * \operatorname{Re}^{0.8} \operatorname{Pr}^{0.333} k A / D h \text { for } \operatorname{Re}>2000 \text { (Colburn equation) }
\end{aligned}
$$

where $q_{1}$ and $q_{2}$ are the heat flux from the stream to the panel, $A$ is the heat transfer area, Re is the Reynolds number, Pr is the Prandtl number, $k$ is the thermal conductivity of the fluid, and $D h$ is the hydraulic diameter of the fluid channel.

\section{Validation of the Radiator Mathematical Models}

Since the radiator will be one of the major components in the ATCS, the transient model must be validated. The radiator studied here is a cylindrical surface divided into eight panels. Two flow loops go through all seven panels in series as shown in Figure 5. The eighth panel does not have flow channels attached to it and remains a panel to close out the structure. Four cases were used for the validation and described as follows.

The first case was low Earth orbit (LEO) hot case at an altitude of $230 \mathrm{~km}, \beta=56^{\circ}$, aft to the Sun, with pitch/yaw/roll/ (P/Y/R) angles of $5 \%-5^{\circ} / 0^{\circ}$. The Thermal Desktop results of the non-dimensional sink temperature and the equivalent heat flux from the environment were plotted in Figures 6(a) and 6(b) for one orbit cycle time of $1.5 \mathrm{hr}$. With a given mass flow rate and the inlet fluid temperature, the computed results of the non-dimensional fluid temperature at the exit of the last panel and the total heat rejection were plotted in Figures 6(c) and 6(d) in comparison with the corresponding Thermal Desktop (TD) results. The maximum difference between the current result and the TD result was less than 2 to 3 percent in the fluid temperature and total heat rejection.

The second case was LEO hot case at the altitude of $230 \mathrm{~km}, \beta=75^{\circ}$, nose forward, with $\mathrm{P} / \mathrm{Y} / \mathrm{R}$ angles of $0^{\circ} / 0^{\circ} / 0^{\circ}$. The environmental heat fluxes were similar to the first case except that the average seven-panel heat flux had abrupt changes for the first case. The corresponding results were plotted in Figure 7 showing a similar agreement as in the first case. 
The third case was lunar transit, aft to the Sun, with $\mathrm{P} / \mathrm{Y} / \mathrm{R}$ angles of $0^{\circ} / 0^{\circ} / 0^{\circ}$. It was a cold steadystate case. The non-dimensional fluid exit temperature maximum difference between the two solution sets was within 1.5 percent as shown in Figure 8.

The fourth case was low lunar orbit (LLO) hot case at an altitude of $90 \mathrm{~km}, \beta=0^{\circ}$, nose forward, with $\mathrm{P} / \mathrm{Y} / \mathrm{R}$ angles of $0^{\circ} / 0^{\circ} / 0^{\circ}$. The non-dimensional sink temperautre and the equivalent orbit heating flux were plotted in Figure 9 for an orbit time of $2 \mathrm{hr}$. It can be seen that the environment is more severe and could be extremely hot and cold. The computed fluid temperature and heat rejection results show similar trend as shown in TD results.

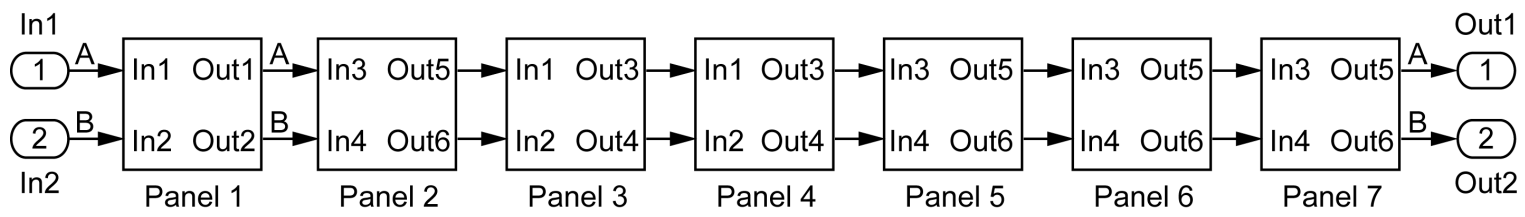

Figure 5.-Seven-panel radiator with two fluid loops.
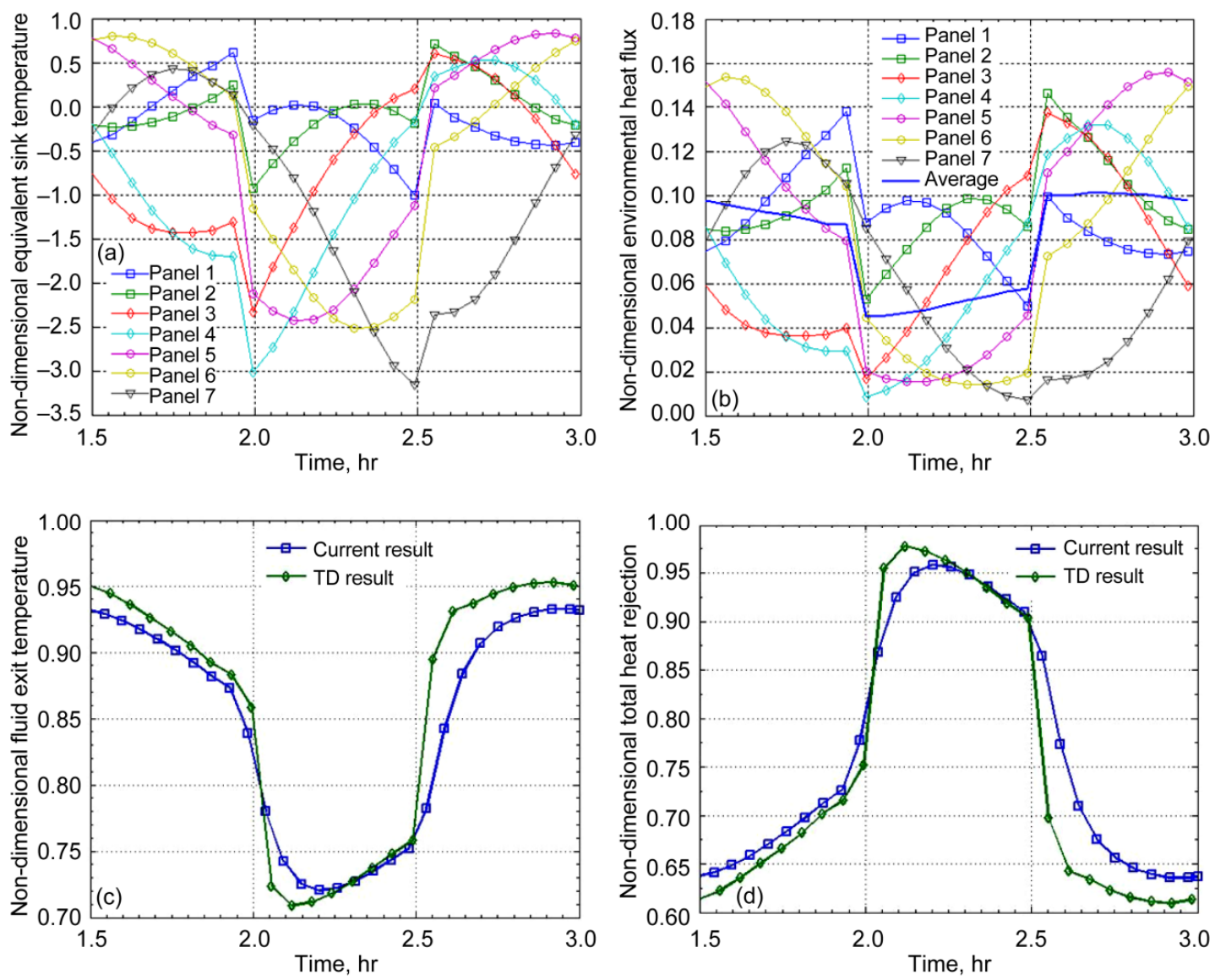

Figure 6.-Results for case 1: Low Earth orbit (LEO) aft-to-Sun hot. (a) Sink temperature. (b) Equivalent orbit heating. (c) Fluid exit temperature. (d) Total heat rejection. 

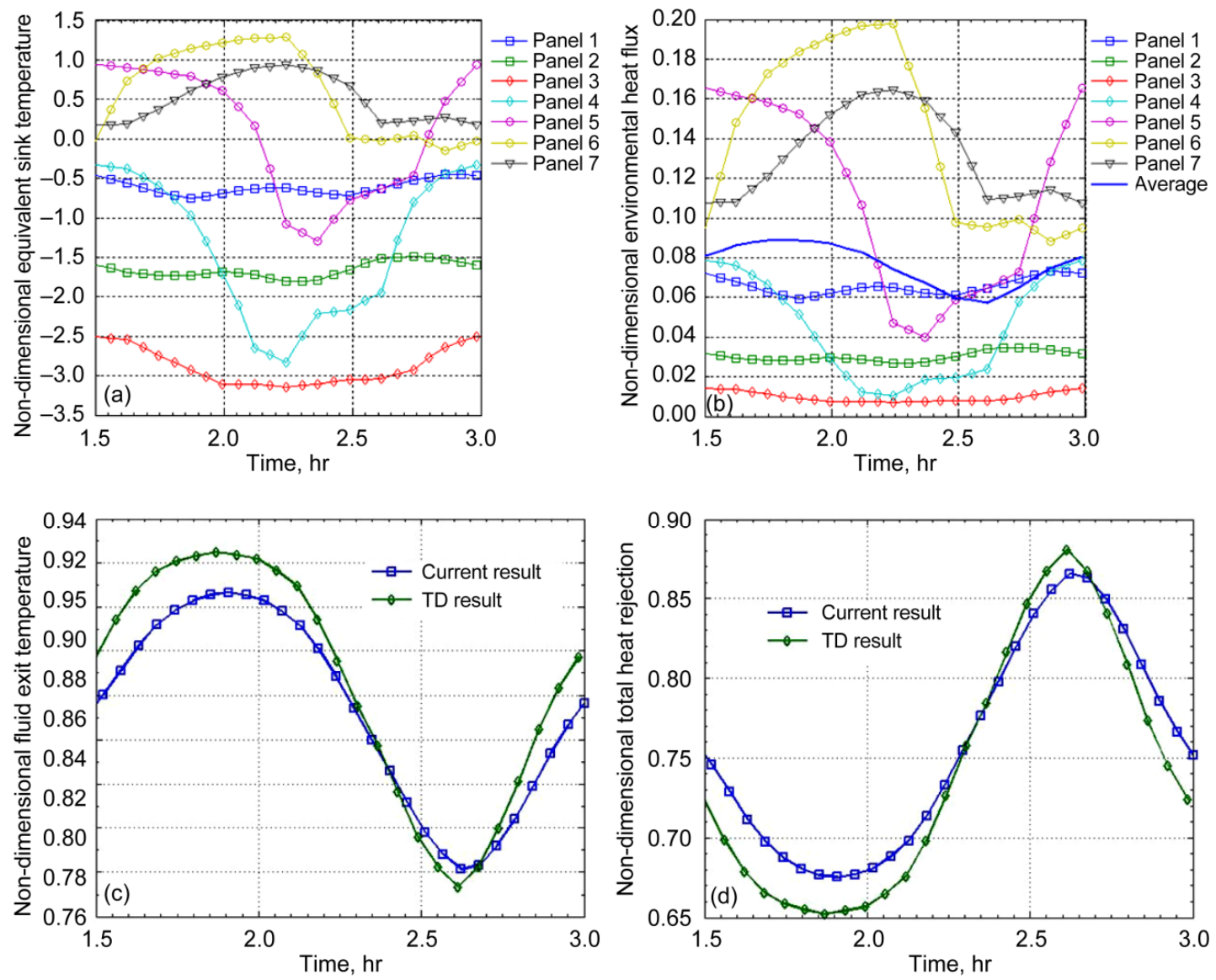

Figure 7.-Results for case 2: LEO nose-forward hot. (a) Sink temperature. (b) Equivalent orbit heating. (c) Fluid exit temperature. (d) Total heat rejection. 

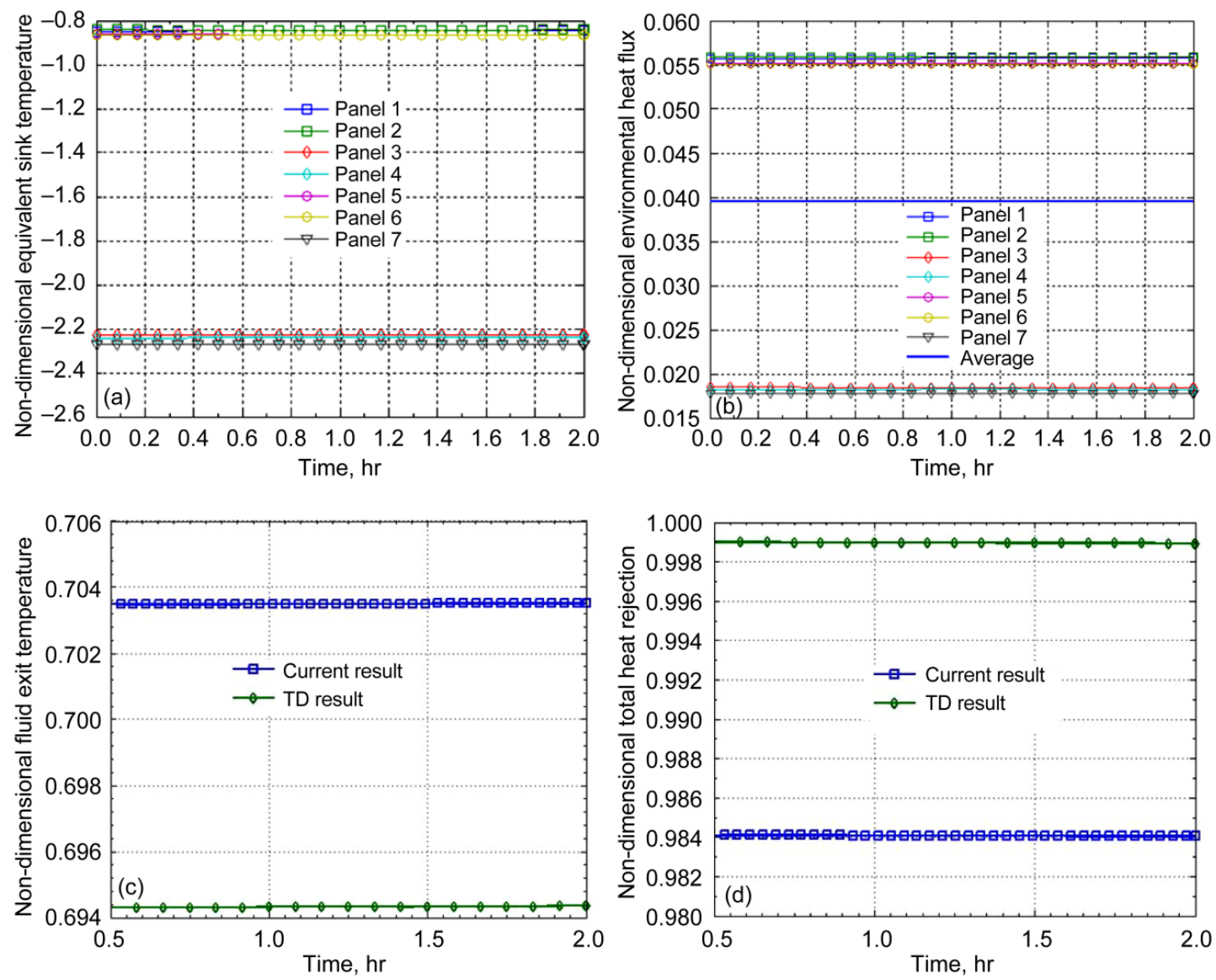

Figure 8.-Results for case 3: Lunar-transit, aft-to-Sun cold. (a) Sink temperature. (b) Equivalent orbit heating. (c) Fluid exit temperature. (d) Total heat rejection. 

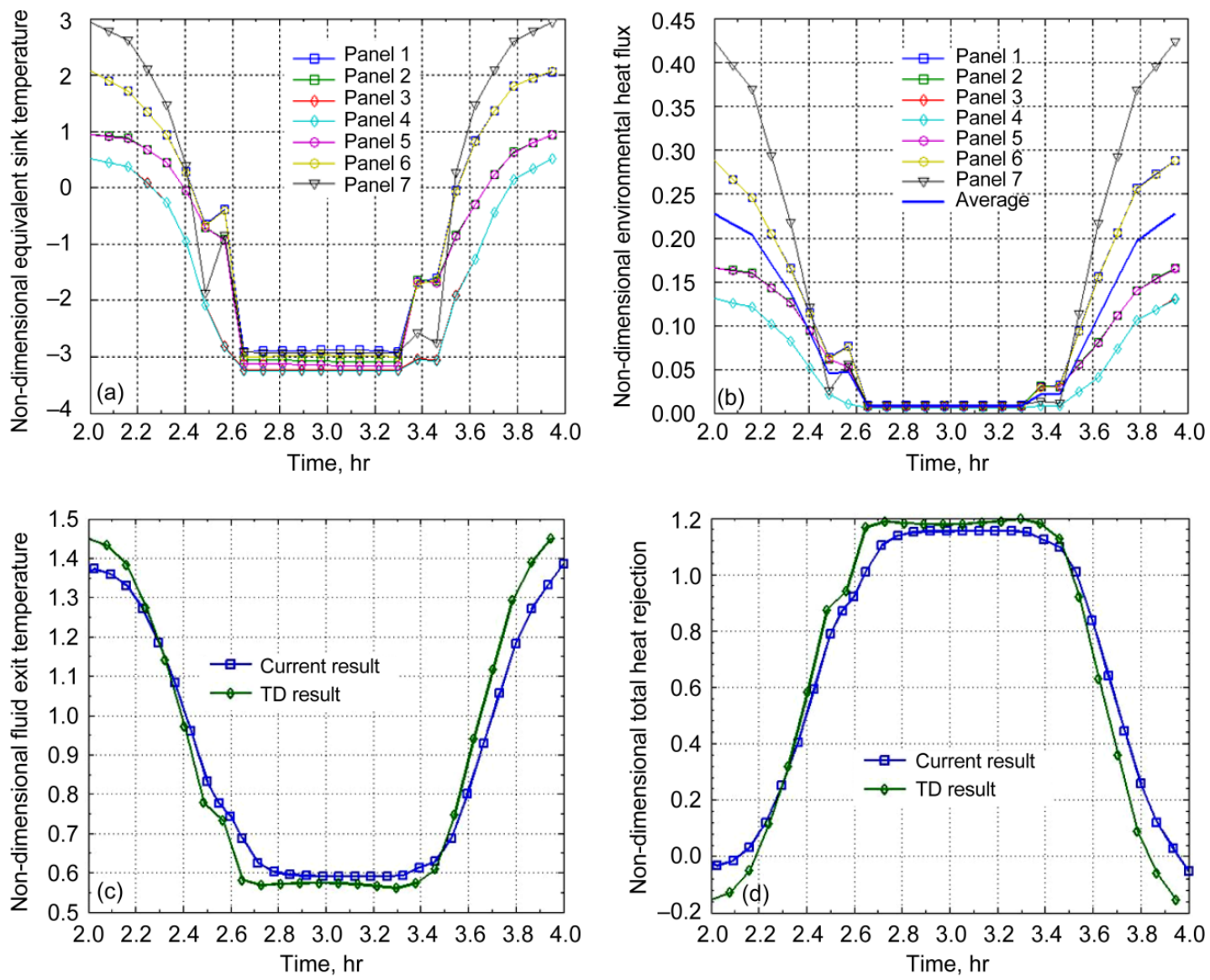

Figure 9.-Results for case 4: Low lunar orbit (LLO), nose-forward hot. (a) Sink temperature. (b) Equivalent orbit heating. (c) Fluid exit temperature. (d) Total heat rejection. 
In summary, the one-dimensional transient model results agree reasonably well with the threedimensional Thermal Desktop model results for all four orbits. It can be concluded that the onedimensional transient model for the radiator can capture the radiator performance accurately.

\section{Active Thermal Control System Model Validation}

The ATCS for the ISS mission will have an eight-panel radiator with no PCM HX, whereas the ATCS for the lunar mission will have a seven-panel radiator with a PCM HX since the LLO environment is generally much worse than that in LEO.

Three orbit cases were used for validation. The first case was for an ISS mission, LEO aft-to-Sun hot at an altitude of $230 \mathrm{~km}, \beta=75^{\circ}, \mathrm{P} / \mathrm{Y} / \mathrm{R}$ angles of $5^{\circ} /-5^{\circ} / 0^{\circ}$, and a power load of $4683 \mathrm{~W}$; The second case was for a lunar mission, LLO nose-nadir hot at an altitude of $75 \mathrm{~km}, \beta=0^{\circ}, \mathrm{P} / \mathrm{Y} / \mathrm{R}$ angles of $-20^{\circ} / 20^{\circ} / 0^{\circ}$, and a power load of $2571 \mathrm{~W}$; and the third case also was for a lunar mission, LLO aft-to-Sun cold at an altitude of $400 \mathrm{~km}, \beta=90^{\circ}, \mathrm{P} / \mathrm{Y} / \mathrm{R}$ angles of $0^{\circ} / 0^{\circ} / 0^{\circ}$, and a power load of $1725 \mathrm{~W}$.

Four sets of solution were compared: (1) current Simulink model results, (2) an independent Simulink model results, (3) SINDA/FLUINT model results, and (4) FloCAD model results. The modeling details of the other three models were not available. The current Simulink model uses the same heat transfer characteristic of all HXs in the ATCS as those used in other three models. The SINDA/FLUINT model has a full three-dimensional radiator model. All models use a similar mathematical approach. Simulink is a commercial tool for modeling, simulating and analyzing multidomain dynamic systems. SINDA/FLUINT is a comprehensive finite-difference, lumped parameter (circuit or network analogy) tool for heat transfer design analysis and fluid flow analysis in complex systems. FloCAD is a Thermal Desktop module that allows a user to develop and integrate both fluid and thermal systems within a CAD based environment. Like Thermal Desktop, FloCAD is a graphical user interface for SINDA/FLUINT.

In the current Simulink/MATLAB model, 20 mesh points are used in the flow direction for the IFHX, 30 mesh points are used in the flow direction for the Regen HX, and two mesh points are used in the flow direction for the sublimator and PCM HX. The heat transfer rate for the IFHX, Regen HX, sublimator, and PCM HX were referred to in Reference 5. For the cabin HX and cold plate for the CM and SM sides, a constant heat load based on the power load was imposed. For the radiator, two mesh points were used for each panel, and all panels were modeled.

The solver used in the Simulink model is ODE45(Dormand-Prince) with a variable time step. The maximum $\Delta t$ was $0.5 \mathrm{~s}$, otherwise the result would have diverged. The model took approximately $20 \mathrm{~min}$ to simulate a three-orbit (4.5-hr) run.

For each case, the non-dimensional fluid temperatures on the CM side (including the cabin inlet, SM cold plate inlet, IFHX inlet, PCM inlet, and sublimator inlet) and the fluid temperatures on the SM side (including the IFHX cold side exit, Regen HX exit, and radiator exit temperature) were plotted. The IFHX bypass flow fraction and Regen HX bypass flow fraction also were plotted. Four sets of solution were plotted side by side for comparison.

Figure 10 shows plots of the non-dimensional Thermal Desktop results of the sink temperature for the eight radiator panels for the LEO aft-to-Sun hot case. Figures 11 and 12 show plots of the all four model results for both the CM and SM sides. The non-dimensional sink temperature changed from -1.70 to 0.55 , showing a mild orbit heating environment. All four model results show similar trends for the IFHX bypass flow changes and a similar on-and-off pattern for the sublimator. Some oscillations exist in the FloCAD model because of the algorithm for turning the sublimator water on and off. On the SM side, all four models show that the Regen HX is not used. 


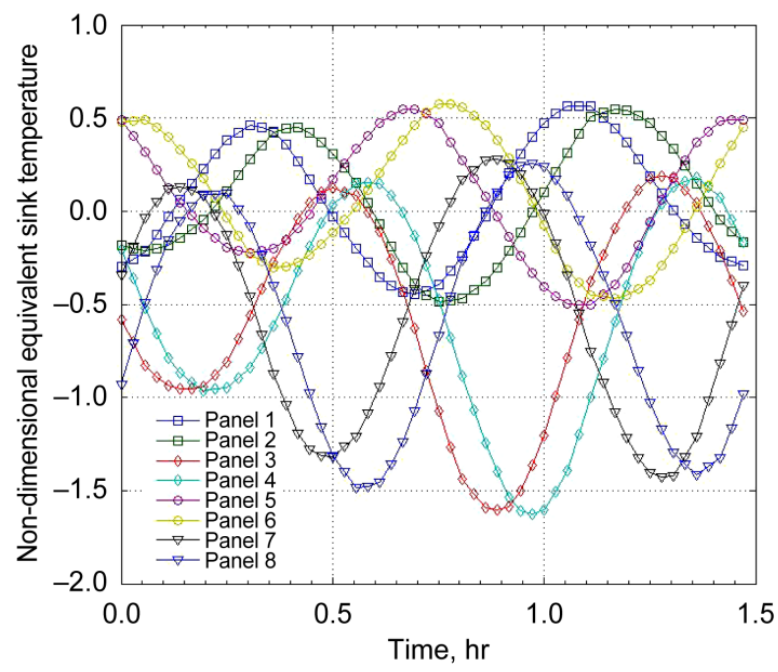

Figure 10.-Sink temperature for LEO aft-to-Sun hot case.

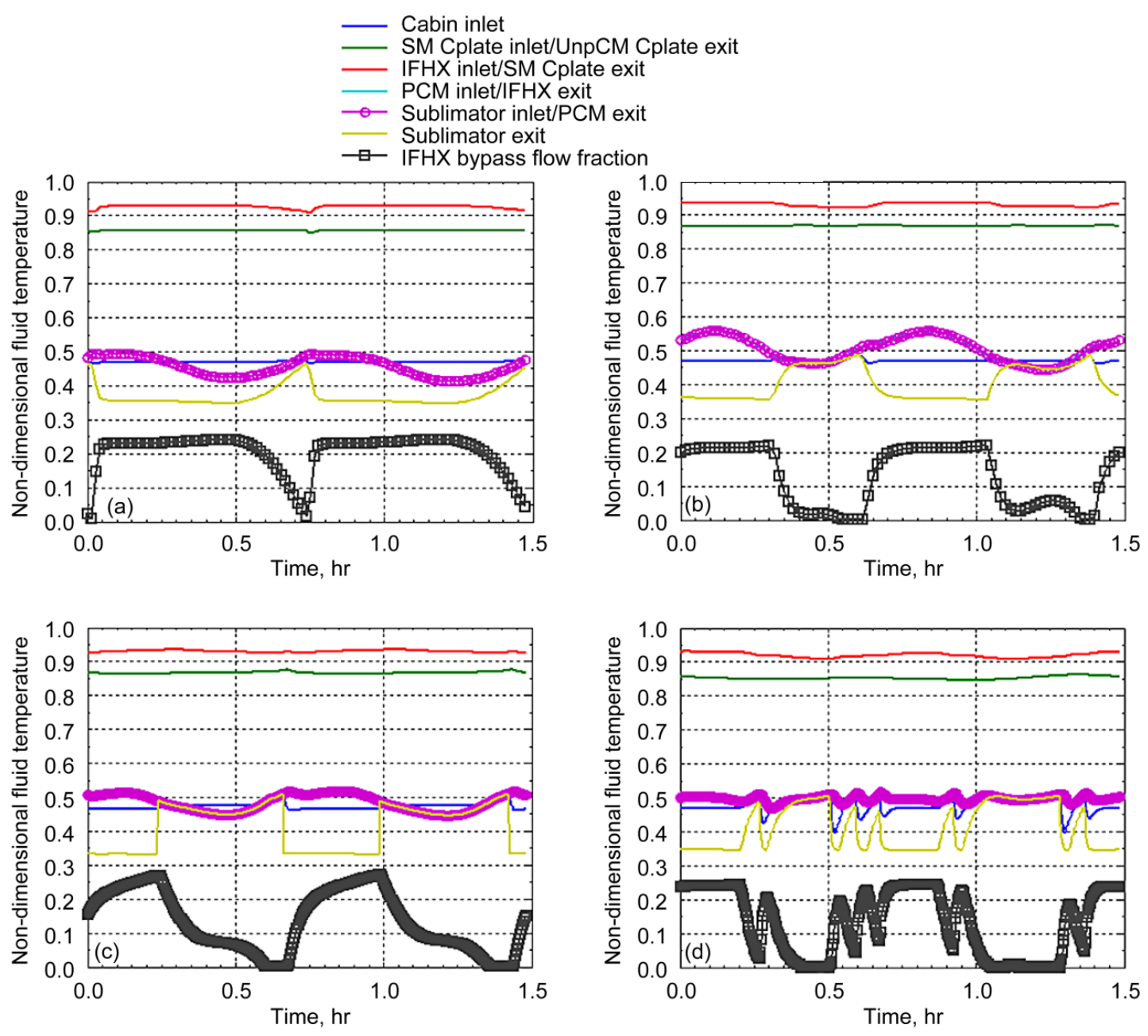

Figure 11.-Crew module (CM) fluid temperature in ATCS for LEO aft-to-Sun hot case. PCM, phase-change material. (a) Current Simulink model. (b) Independent Simulink model. (c) SINDA/FLUINT model. (d) FloCAD model. 

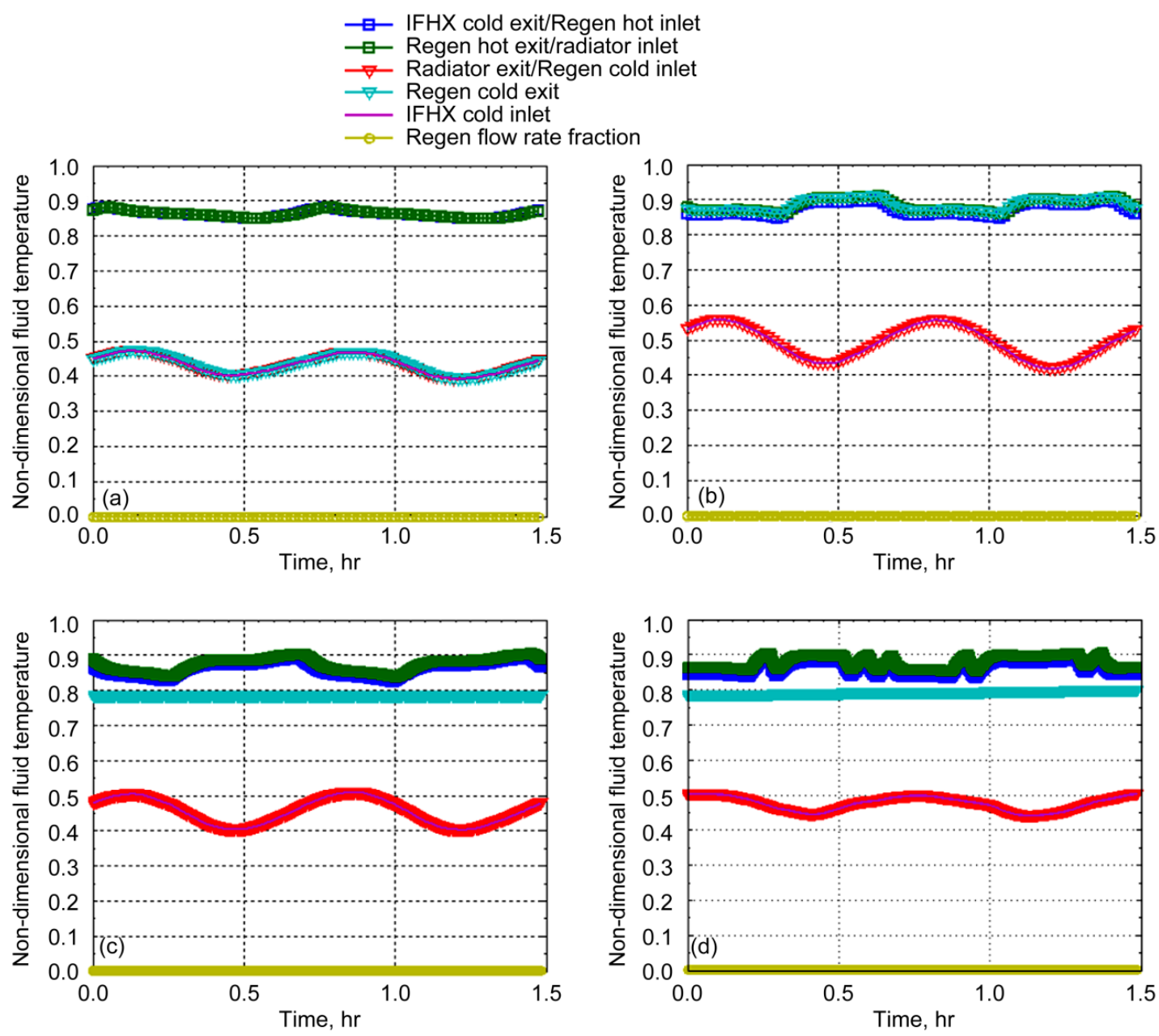

Figure 12.-Service module (SM) fluid temperature in ATCS for LEO aft-to-Sun hot case. (a) Current Simulink model. (b) Independent Simulink model. (c) SINDA/FLUINT model. (d) FloCAD model.

Figures 13 to 15 show the corresponding results for the second case. The sink temperature varied from -2.50 to 1.20 . On the CM side, all models show a maximum IFHX bypass flow rate of 50 to 54 percent. On the SM side, all models show a similar pattern of Regen HX bypass flow changes. The maximum Regen HX flow rate was 40 to 65 percent. The fluid temperature drop across the radiator was similar for all the models: there was a 0.33 to 0.34 drop when the Regen HX was operating at the maximum flow rate. The difference in the Regen HX flow percentage could be due to the varying performance of the Regen HX. However, the total heat rejection should be similar for all models. When the Regen HX has no flow passing through, each model has different ways of book keeping the Regen cold exit temperatures, as shown in Figure 15. The Regen cold exit temperature is not used in the model when no flow goes through regen HX.

For the third case - a steady-state cold case - very good agreement was achieved, as shown in Figures 16 to 18 . The sink temperature changed from -1.60 to -0.60 . On the CM side, all models show a 68- to 69-percent IFHX bypass flow. On the SM side, the current model and SINDA/FLUINT model show 78 to 80 percent flow to the Regen HX flow, FloCAD data show 90 percent flow to the Regen HX. For all models, the temperature drop across the radiator panel was approximately 0.20 . 


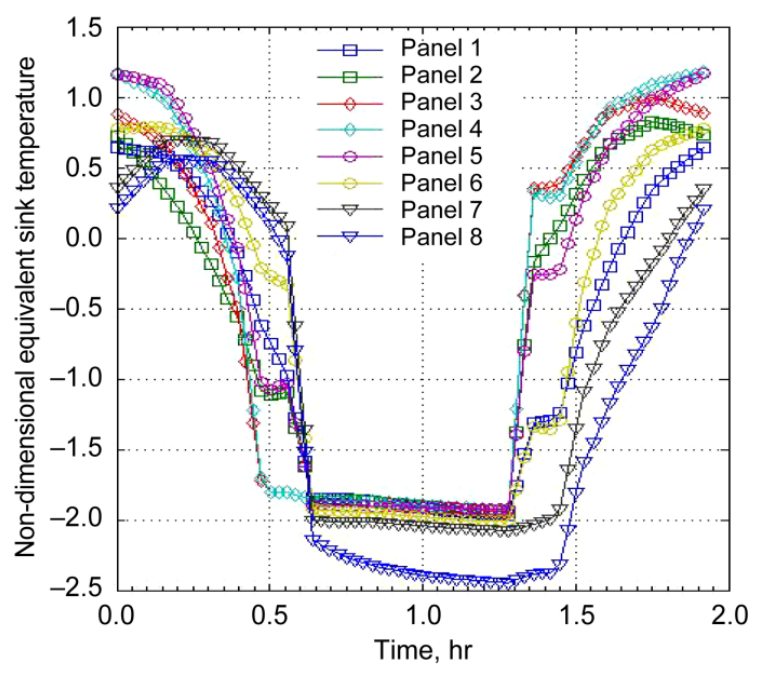

Figure 13.-Sink temperature for LLO nose-nadir hot case.
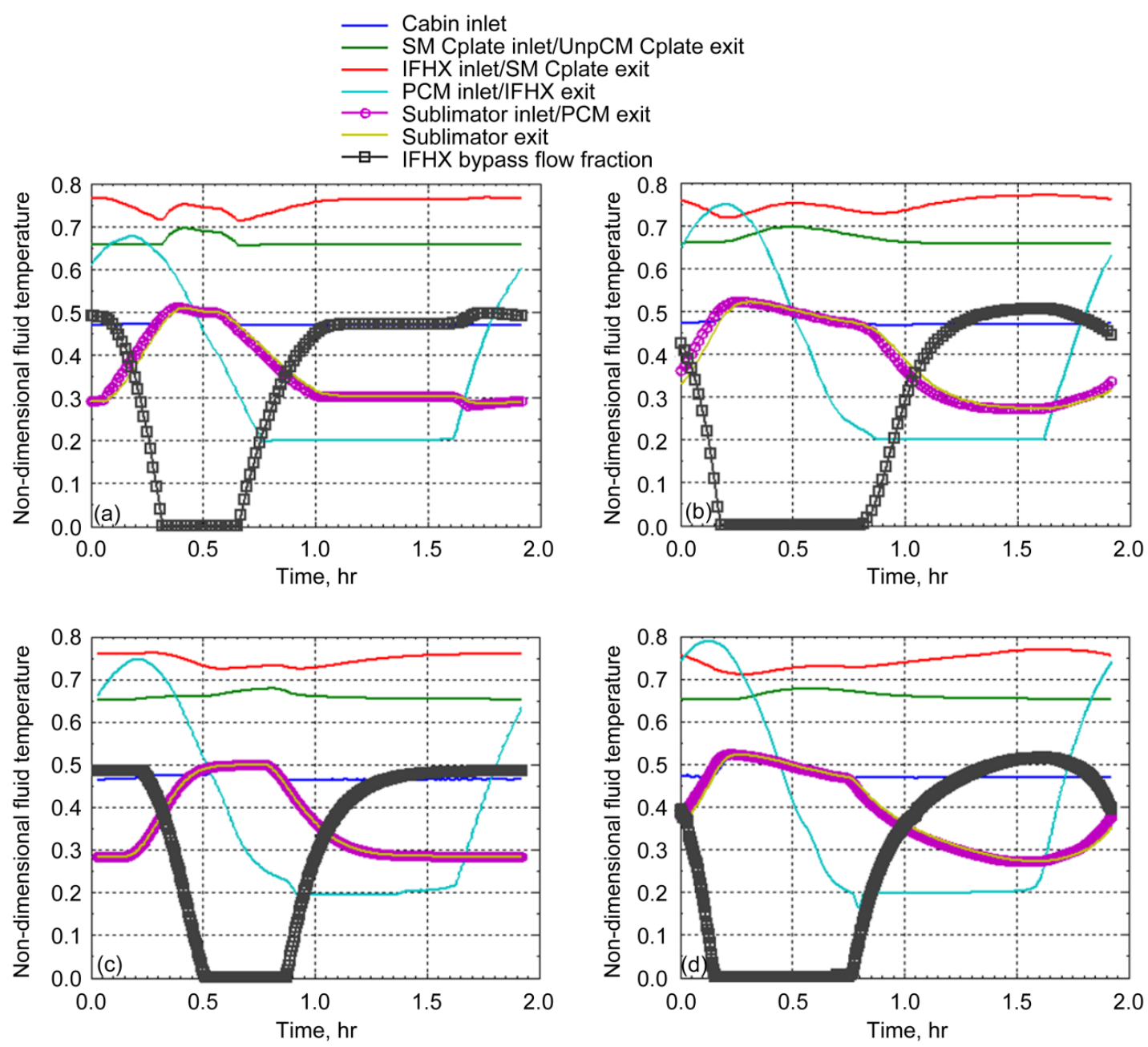

Figure 14.-CM fluid temperature in ATCS for LLO nose-nadir hot case. (a) Current Simulink model. (b) Independent Simulink model. (c) SINDA/FLUINT model. (d) FloCAD model. 

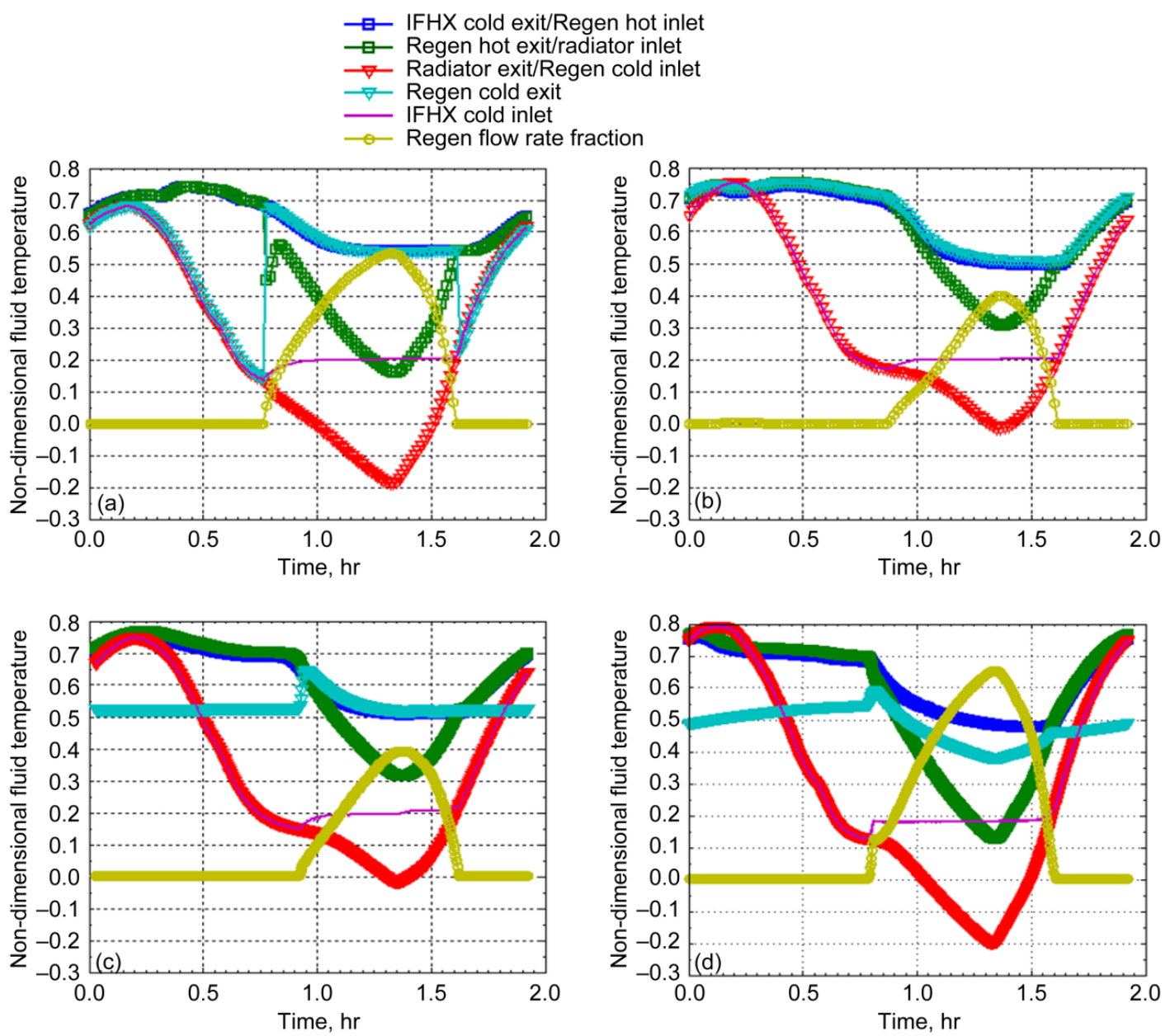

Figure 15.-SM fluid temperature in ATCS for LLO nose-nadir hot case. (a) Current Simulink model. (b) Independent Simulink model. (c) SINDA/FLUINT model. (d) FloCAD model. 


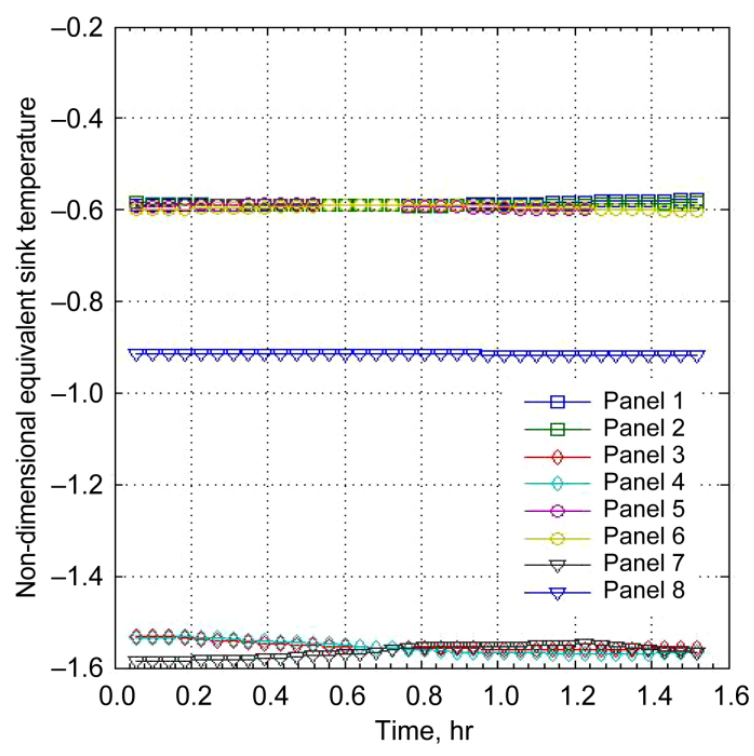

Figure 16.-Sink temperature for LLO aft-to-Sun cold case.
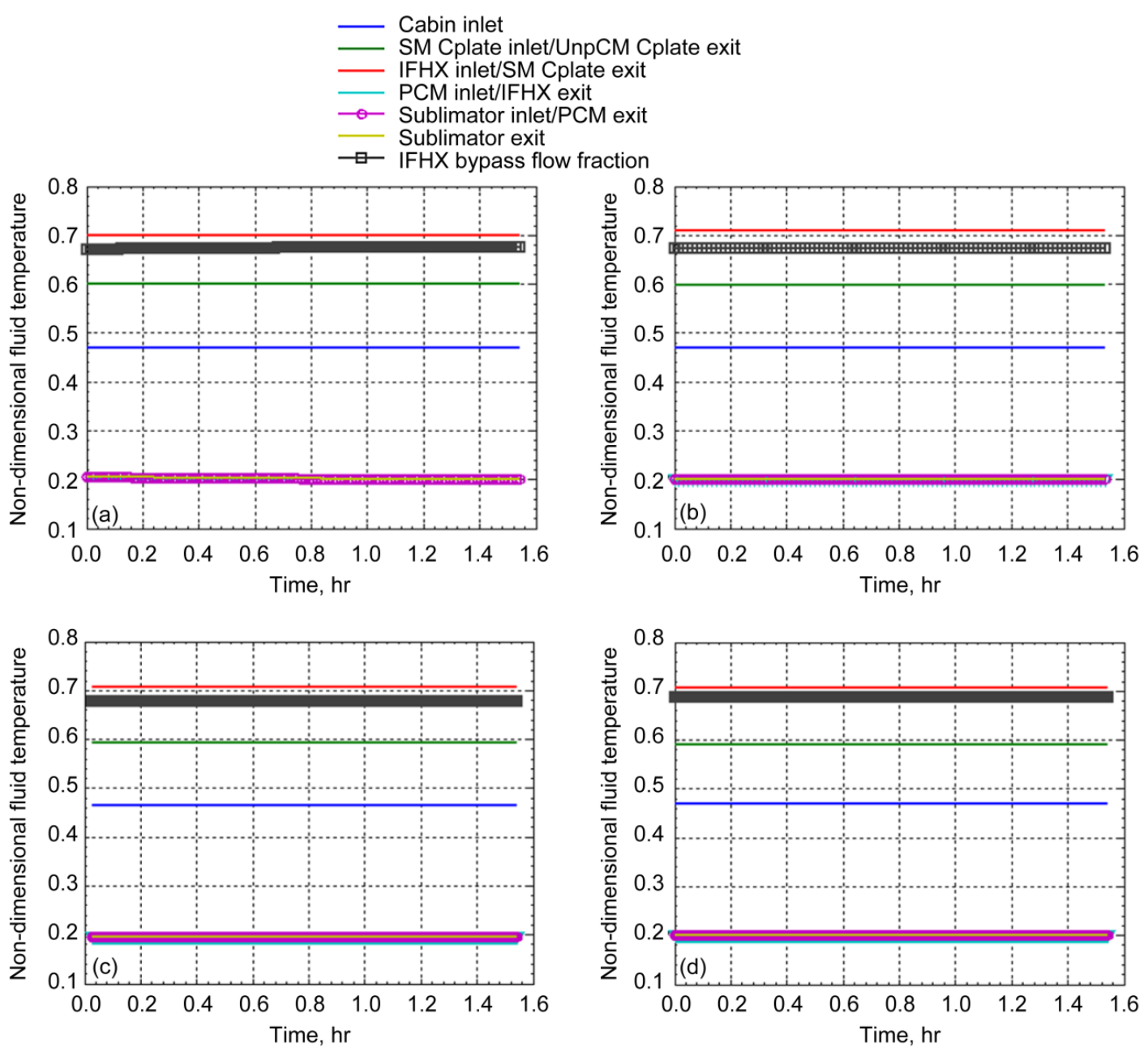

Figure 17.-CM fluid temperature in ATCS for LLO aft-to-Sun cold case. (a) Current Simulink model. (b) Independent Simulink model. (c) SINDA/FLUINT model. (d) FloCAD model. 

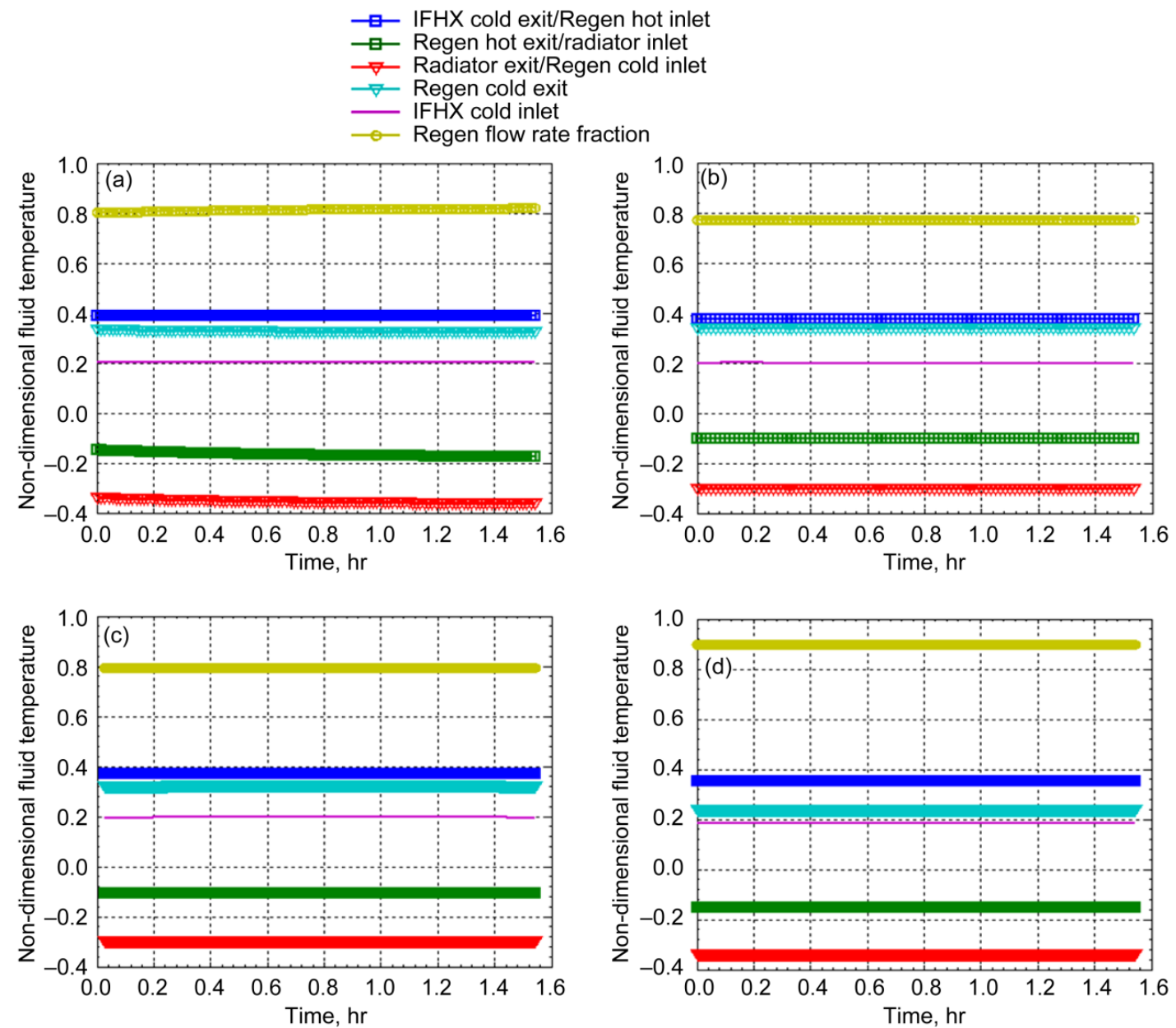

Figure 18.-SM fluid temperature in ATCS for LLO aft-to-Sun cold case. (a) Current Simulink model. (b) Independent Simulink model. (c) SINDA/FLUINT model. (d) FloCAD model.

In summary, there is reasonable agreement among the four models with the possible exception that the control algorithm in each model might be different, which would cause the transient phenomena to be slightly different, as shown in the first and second cases. All four models show simiar trends and performance for the ATCS.

\section{ATCS Performance for a 45-hr Nominal Mission Timeline}

To further demonstrate the capability of this model, a timeline for the 45-hr nominal mission timeline was simulated to show the ATCS performance. During the mission timeline, the attitude of Orion and power loads on the ATCS vary with time. With defined attitude and power load timelines, the ATCS performance is computed and the non-dimensional fluid temperature variations on both the CM and SM sides are plotted in Figures19 and 20. The non-dimesnional heat rejection is shown in Figure 21. During the first $45 \mathrm{hr}$ before docking, the ATCS was relatively "cool" compared with some hot cases studied previously. The radiator fluid inlet temperature was within 0.40 to 0.60 most of the time. The Regen HX was on most of the time, whereas the maximum regenerative flow rate was approximately 50 percent. The sublimator turned off at $t=18 \mathrm{~min}$ and stayed off. The total sublimated water was $2.3 \mathrm{lbm}$. Note that ascent heating was not included here. The model took approximately $3 \mathrm{hr}$ to simulate for the 45 -hr run. 


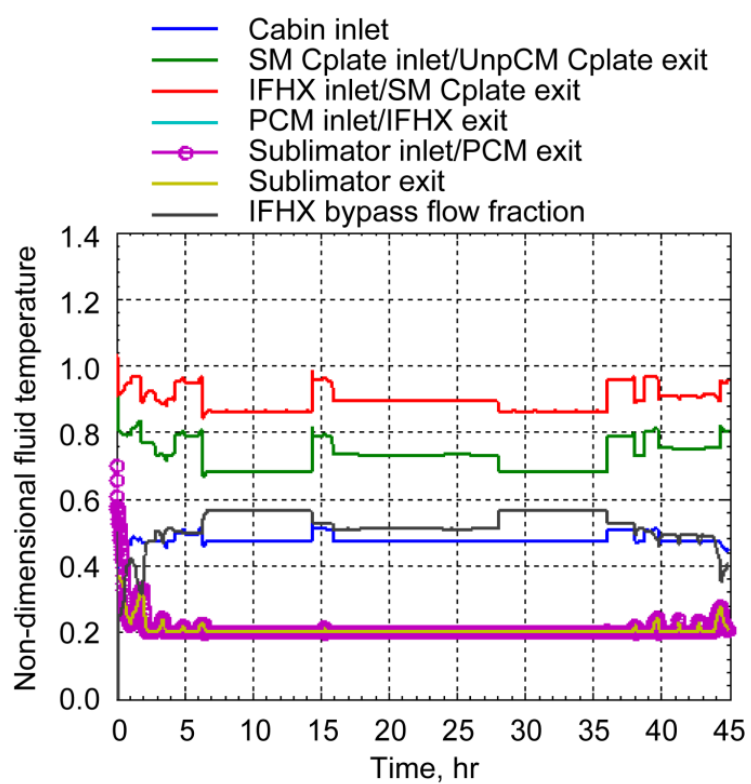

Figure 19.-Fluid temperature on CM side for 45-hr nominal mission timeline.

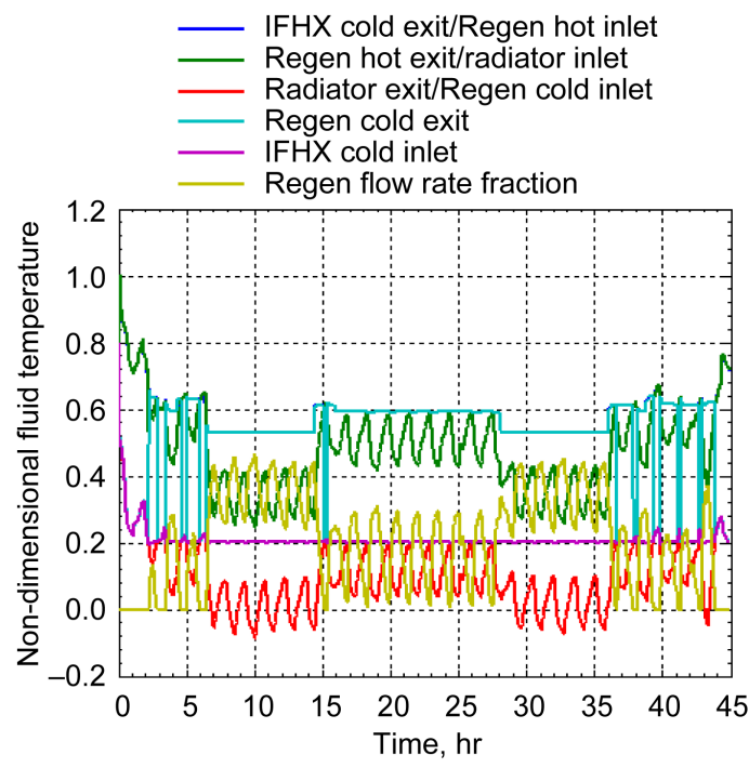

Figure 20.-Fluid temperature on SM side for 45-hr nominal mission timeline. 


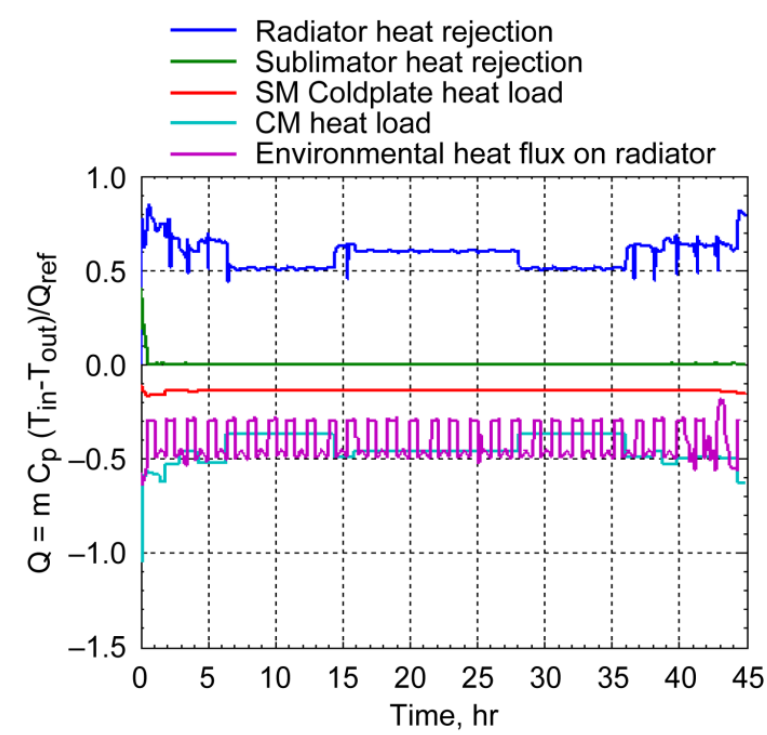

Figure 21.- - Heat rejection and power load for 45-hr nominal mission timeline.

\section{Conclusions}

A dynamic Simulink model of the Orion ATCS was presented. Details of the mathematical models of the heat exchanger and radiator were described. The active thermal control system model was validated using three different orbits by comparing the corresponding three results from independent resources. The agreement of the results for all four models is reasonable. All four models predict similar ATCS behavior for all three cases. Some unexplained discrepancies exist among the four models and are thought to be due to possible variations in the control algorithm used in each model. Control algorithm details were not available for this study.

\section{References}

1. Simulink, developed by The MathWorks.

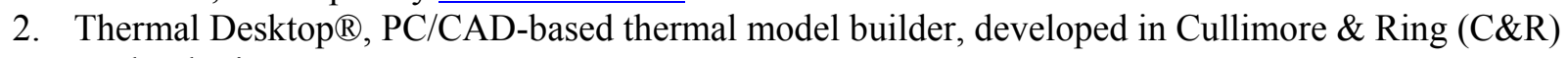
Technologies.

3. FloCAD ${ }^{\circ}, P C / C A D-b a s e d$ thermal/fluid model builder, developed in $\mathrm{C} \& \mathrm{R}$ Technologies.

4. SINDA/FLUINT, a generalized thermal/fluid network-style solver.

5. NASA and Lockheed Martin Orion thermal technical interchange meeting (TIM), Dec. 2008. 


\begin{tabular}{|c|c|c|}
\hline \multicolumn{2}{|c|}{ REPORT DOCUMENTATION PAGE } & $\begin{array}{l}\text { Form Approved } \\
\text { OMB No. 0704-0188 }\end{array}$ \\
\hline \multicolumn{3}{|c|}{ 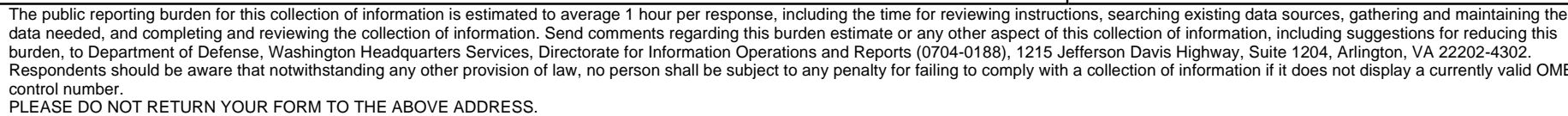 } \\
\hline $\begin{array}{l}\text { 1. REPORT DATE (DD-MM-YYYY) } \\
01-05-2010\end{array}$ & $\begin{array}{l}\text { 2. REPORT TYPE } \\
\text { Technical Memorandum }\end{array}$ & 3. DATES COVERED (From - To) \\
\hline \multirow{3}{*}{\multicolumn{2}{|c|}{$\begin{array}{l}\text { 4. TITLE AND SUBTITLE } \\
\text { Orion Active Thermal Control System Dynamic Modeling Using S }\end{array}$}} & 5a. CONTRACT NUMBER \\
\hline & & 5b. GRANT NUMBER \\
\hline & & 5c. PROGRAM ELEMENT NUMBER \\
\hline \multirow{3}{*}{\multicolumn{2}{|c|}{$\begin{array}{l}\text { 6. AUTHOR(S) } \\
\text { Wang, Xiao-Yen, J.; Yuko, James }\end{array}$}} & 5d. PROJECT NUMBER \\
\hline & & 5e. TASK NUMBER \\
\hline & & $\begin{array}{l}\text { 5f. WORK UNIT NUMBER } \\
\text { WBS 644423.06.32.01.03 }\end{array}$ \\
\hline \multicolumn{2}{|c|}{$\begin{array}{l}\text { 7. PERFORMING ORGANIZATION NAME(S) AND ADDRESS(ES) } \\
\text { National Aeronautics and Space Administration } \\
\text { John H. Glenn Research Center at Lewis Field } \\
\text { Cleveland, Ohio 44135-3191 }\end{array}$} & $\begin{array}{l}\text { 8. PERFORMING ORGANIZATION } \\
\text { REPORT NUMBER } \\
\text { E-17146 }\end{array}$ \\
\hline \multirow{2}{*}{\multicolumn{2}{|c|}{$\begin{array}{l}\text { 9. SPONSORING/MONITORING AGENCY NAME(S) AND ADDRESS(ES) } \\
\text { National Aeronautics and Space Administration } \\
\text { Washington, DC 20546-0001 }\end{array}$}} & $\begin{array}{l}\text { 10. SPONSORING/MONITOR'S } \\
\text { ACRONYM(S) } \\
\text { NASA }\end{array}$ \\
\hline & & $\begin{array}{l}\text { 11. SPONSORING/MONITORING } \\
\text { REPORT NUMBER } \\
\text { NASA/TM-2010-216252 }\end{array}$ \\
\hline \multicolumn{3}{|c|}{$\begin{array}{l}\text { 12. DISTRIBUTION/AVAILABILITY STATEMENT } \\
\text { Unclassified-Unlimited } \\
\text { Subject Categories: } 34 \text { and } 64 \\
\text { Available electronically at http://gltrs.grc.nasa.gov } \\
\text { This publication is available from the NASA Center for AeroSpace Information, 443-757-5802 }\end{array}$} \\
\hline
\end{tabular}

\section{SUPPLEMENTARY NOTES}

\section{ABSTRACT}

This paper presents dynamic modeling of the crew exploration vehicle (Orion) active thermal control system (ATCS) using Simulink (Simulink, developed by The MathWorks). The model includes major components in ATCS, such as heat exchangers and radiator panels. The mathematical models of the heat exchanger and radiator are described first. Four different orbits were used to validate the radiator model. The current model results were compared with an independent Thermal Desktop (TD) (Thermal Desktop, PC/CAD-based thermal model builder, developed in Cullimore \& Ring (C\&R) Technologies) model results and showed good agreement for all orbits. In addition, the Orion ATCS performance was presented for three orbits and the current model results were compared with three sets of solutionsFloCAD (FloCAD, PC/CAD-based thermal/fluid model builder, developed in C\&R Technologies) model results, SINDA/FLUINT (SINDA/FLUINT, a generalized thermal/fluid network-style solver ) model results, and independent Simulink model results. For each case, the fluid temperatures at every component on both the crew module and service module sides were plotted and compared. The overall agreement is reasonable for all orbits, with similar behavior and trends for the system. Some discrepancies exist because the control algorithm might vary from model to model. Finally, the ATCS performance for a 45-hr nominal mission timeline was simulated to demonstrate the capability of the model. The results show that the ATCS performs as expected and approximately $2.3 \mathrm{lb}$ water was consumed in the sublimator within the $45 \mathrm{hr}$ timeline before Orion docked at the International Space Station.

\section{SUBJECT TERMS}

Active thermal control system; Dymanic modeling; Spacecraft

\begin{tabular}{|c|c|c|c|c|c|}
\hline \multicolumn{3}{|c|}{ 16. SECURITY CLASSIFICATION OF: } & \multirow{2}{*}{$\begin{array}{l}\text { 17. LIMITATION OF } \\
\text { ABSTRACT } \\
\text { UU }\end{array}$} & \multirow{2}{*}{$\begin{array}{l}\text { 18. NUMBER } \\
\text { OF } \\
\text { PAGES } \\
25\end{array}$} & \multirow{2}{*}{$\begin{array}{l}\text { 19a. NAME OF RESPONSIBLE PERSON } \\
\text { STI Help Desk (email:help@sti.nasa.gov) } \\
\text { 19b. TELEPHONE NUMBER (include area code) } \\
\text { 443-757-5802 }\end{array}$} \\
\hline $\begin{array}{l}\text { a. REPORT } \\
\mathrm{U}\end{array}$ & $\begin{array}{l}\text { b. ABSTRACT } \\
\mathrm{U}\end{array}$ & $\begin{array}{l}\text { c. THIS } \\
\text { PAGE } \\
\text { U }\end{array}$ & & & \\
\hline
\end{tabular}



